Chapter 10

\title{
Alzheimer Disease: The Role of $A \beta$ in the Glutamatergic System
}

\author{
Victoria Campos-Peña and \\ Marco Antonio Meraz-Ríos \\ Additional information is available at the end of the chapter \\ http://dx.doi.org/10.5772/57367
}

\section{Introduction}

The beta amyloid hypothesis is the most accepted theory explaining the pathophysiology of Alzheimer's disease (AD). In general terms, it is known that AD is characterized by a chronic and progressive neurodegenerative process involving the intracellular and extracellular accumulation of fibrillary proteins. The presence of these aggregates leads to synaptic and neuronal loss observed in Alzheimer's patients. Although the precise etiology of AD is unknown, the main risk factor is advanced age. It is also known that a small proportion of AD patients have an autosomal dominant inheritance pattern in three genes - amyloid precursor protein $(\mathrm{A} \beta \mathrm{PP})$, presenilin 1 (PS1) and presenilin 2 (PS2) [1-6]. The presence of specific mutations in these genes leads to the premature development of the disease, known as Early Onset Alzheimer's Disease (EOAD) or Familial Alzheimer's Disease (FAD). The most common mutations are located in the presenilin genes [1,7-9], mainly in PS1. Currently more than 185 mutations in PS1 have been reported, with only 13 mutations in PS2. While these mutations are located along the length of the protein sequence, the majority is found in the transmembrane area, and affects protein function. To date, approximately 36 different missense mutations in the APP gene have been identified in 85 families and are located near sites that are recognized by alpha, beta and gamma secretases, thus affecting protein processing and increasing the production of amyloid peptides [10]. The presence of these mutations is a causal factor in the development of $\mathrm{AD}$, and, although they are all related to the disruption of the normal functioning of proteins and an increased formation of beta amyloid, together they are present in less than $10 \%$ of all Alzheimer's cases, suggesting that there are many other nongenetic factors involved in the development of the pathology. The remaining $90 \%$ of AD cases are known as Sporadic Alzheimer's Disease or Late Onset Alzheimer's disease (LOAD). These 
patients also exhibit genetic risk factors, such as the presence of allele 4 of the Apolipoprotein E (Apoc4), where individuals with one copy of $\varepsilon 4$ allele are three times more at risk of developing the disease, while those with two copies $(\varepsilon 4 / \varepsilon 4)$ are 10-15 times more likely to develop AD [11-14]. While other non-genetic factors are head trauma, hypertension, atherosclerosis, metabolic disorders such as hypercholesterolemia, obesity and diabetes [15-17], the main risk factor is age. It has been reported that the incidence of the disease increases by $5 \%$ in people over 65 and $20 \%$ in those over 80 . Other factors have also been associated with the development of the disease, such as female gender, smoking, educational level, and a low level of physical and mental activity during the early stages of life.

The pathological markers for AD are the presence of neurofibrillary tangles (NFT) and neuritic plaques (NP). NFT are intracellular and insoluble fibril deposits of paired helical filaments (PHF). As these filaments occupy the cytoplasm of the neuron, the nucleus is displaced and the dendrites disappear, in the absence of which, the filaments takes on the pyramidal shape of the soma and then go on to destroy the neuron itself. Each filament is formed from the association of 6-7 Tau protein fragments, and each fragment consists of 93-95 amino acid residues and has a molecular weight of $12.5 \mathrm{Kd}$ [18-21]. In normal conditions, Tau stabilizes microtubules in the cytoskeleton of neurons through a cell process that involves the phosphorylation and dephosphorylation of the protein. In pathological conditions, Tau is abnormally hyperphosphorylated and loses its ability to bind to microtubules, generating insoluble aggregates within the neuron, altering the axonal transport and eventually leading to neuronal death. Generally NFT formation begins in the allocortex of the medial temporal lobe (entorhinal cortex and hippocampus) and spreads to the associative isocortex. In this way, the amount and distribution of NFTs correlate with the severity and duration of dementia.

NPs are extracellular deposits of $10-100 \mu \mathrm{m}$ formed by an insoluble fibrillary core surrounded by activated microglia, reactive astrocytes and dystrophic neurites [22]. Unlike NFTs, amyloid plaques accumulate mainly in the isocortex. The main component in the NP is the amyloidbeta peptide $(\mathrm{A} \beta)$; a fragment of 39-42 amino acids with a molecular weight of 4KD [23-24], which arises as a result of the normal secretion derived from amyloid- $\beta$ precursor protein $(\mathrm{A} \beta \mathrm{PP})$ [25]. $\mathrm{A} \beta$ formation occurs as a result of the proteolytic processing of $\mathrm{A} \beta \mathrm{PP}$ by the sequential action of $\beta$ - and $\gamma$-secretase. Three A $\beta P P$ isoforms consisting of 695,770 and 751 amino acids (APP695, APP751 and APP770) are mainly expressed in the Central Nervous System (CNS). The shortest of these isoforms, APP695, is mostly expressed in neurons, whereas isoforms APP770 and APP751 are expressed in glial cells.

It has been proposed that the progressive accumulation of NP and NFT in the brains of AD patients are responsible for the neurodegeneration observed in the hippocampal, cortical and subcortical neurons. This neurodegenerative damage involves the loss of neuropil networks, selective neuron death, decreased synaptic density and alterations in neurotransmitters and the homeostasis of calcium. An important feature of the NFTs is that the density of such lesions directly correlates with the degree of dementia observed in AD patients [26]. Conversely, it is observed that the number of NP present in a particular region does not correlate with neuronal death, synaptic loss or with cognitive impairment [27-29]. However, the presence of A $\beta$ oligomer deposits has a very important role in synaptic loss [30-32] determining the severity 
of cognitive impairment. Also has been observed to inhibit the normal critical neuron functions, such as long-term potentiation (LTP)[30]. The amyloid $\beta$ peptide, also increases Tau phosphorylation [33-35], oxidative stress and altered homeostasis of $\mathrm{Ca}^{2+}$ [36-37] and excitotoxicity [38]. It has been documented that these oligomeric forms of $A \beta$ interact with receptors from the glutamatergic system such as the NMDA-receptors, which are responsible for maintaining glutamate homeostasis [39-40].

\section{1. $\beta$-Amyloid}

$\mathrm{A} \beta$ comes from the normal proteolytic processing of $\mathrm{A} \beta \mathrm{PP}$, a type 1 transmembrane glycoprotein [25] whose gene is located on chromosome 21 [41-42]. A $\beta P P$ processing and the "efficiency" of $A \beta$ formation could be affected by the subcellular localization of the protein. $\mathrm{A} \beta \mathrm{PP}$ is synthesized in the endoplasmic reticulum (ER) and transported through the constitutive secretory pathway, and only a small fraction of this protein $(10 \%)$ goes to the plasma membrane. All A $\beta P P$ isoforms undergo posttranslational modifications involving $\mathrm{N}$ and $\mathrm{O}-$ glycosylation, phosphorylation and sulfation. A $\beta$ peptide formation is carried out by the action of $\beta$ - and $\gamma$-secretase, in which the peptides formed vary from 39 to 43 amino-acid residues (A $\beta 39,40,42,43)$. Although $\mathrm{A} \beta 40$ is the most abundant, $\mathrm{A} \beta 42$ is the most hydrophobic and is found in a greater proportion of the NPs observed in AD patients [43]. These peptides are continuously released into the extracellular space at possibly low concentrations, and, in soluble form, could carry out normal physiological functions in the cell including those related to plasticity and memory processes [44].

According to the amyloid hypothesis, the $\mathrm{A} \beta$ accumulation in the patient's brain is the key event that leads to the development of the disease, while other pathological findings (NFT formation and neuronal death) are secondary events occurring after the amyloid aggregation. Most of the studies reported in the literature have focused on the toxicity and neuronal death induced by the presence of amyloid aggregates. However, in recent years a great importance has been attached to the role of these peptides as responsible in the etiology of synaptic dysfunction[40]. In this sense, it has been widely documented that the presence of soluble oligomeric forms of $A \beta$ responsible for synaptic damage and neurodegeneration [29, 45-46]. The results reported in the literature indicate that $\mathrm{A} \beta$ oligomers ranging in size from 2 to 12 subunits may be responsible for the synaptic damage and memory loss observed in patients with Alzheimer's disease [47]. These oligomeric forms may be produced through several routes, either in the extracellular space or inside of the cell organelles such as the endoplasmic reticulum and mitochondria, which complicates the analysis and understanding of the pathophysiology [48-50]. Several types of soluble $A \beta$ oligomers have been described in the brains of $\mathrm{AD}$ patients and in transgenic mouse models of $\mathrm{AD}$, however it has been reported that the putative dodecamer $A \beta * 56$ correlated with markers of neuronal dysfunction or injury in cognitively normal subjects [51]. In addition, the role of $A \beta$ oligomers (in the absence of amyloid fibers) in neurodegenerative processes was demonstrated in a transgenic model expressing mutant $\mathrm{hAPP} \mathrm{E}_{693 \Delta}$. This mouse has the ability to form high levels of $\mathrm{A} \beta$ oligomers without fibrillization, indicating that the intracellular deposits of $A \beta$ oligomers from 8 months of age onwards correlate with the alterations in synaptic plasticity and memory impairment 
observed in the mouse model. Other results observed were abnormal Tau phosphorylation, present at 8 months, microglial activation at 12 months, astrocytes activation at 18 months and neuronal loss at 24 months. The results suggest that the presence of oligomeric forms of $\beta-$ amyloid are able to induce many of the changes observed in the brains of patients with AD, even in the absence of NP [52].

\subsection{Extracellular $A \beta$}

The extracellular deposits of amyloid are a specific marker for AD and are involved in synaptic dysfunction and neurotoxicity; however, the complete signaling mechanism involved remains unclear. Importantly, the amyloid oligomers interact with a variety of receptors on the surface, activating or inhibiting several neuronal signaling pathways and possibly contributing to neuronal death [35]. Furthermore, it is also known that the damage caused by amyloid is mainly determined by the level of peptide aggregation. In this way, several studies reported in the literature suggest that extracellular $A \beta$ oligomers could be formed by several biocomponents, such as proteins and ganglioside. For example, the distribution of ganglioside GM1 has the ability to affect the spatial arrangement of the oligosaccharide chains in a molecule. In 2007 Yamamoto et al. showed that GM1 provides a microenvironment that favors the formation of amyloid oligomers [53]. These oligomers are spherical structures with a 10-20nm diameter and 200-300kDa that form complexes with the GM1, similar to those identified in the tissue of AD patients. Previous studies have shown that, initially, the peptides adopt a random structure, which then changes when interacting with GM1, and enables the transition from $\alpha$-helix to $\beta$-pleated sheets [54]. Similarly, nonfibrillar A $\beta$ can be produced in presence of $\alpha$ Bcrystalline and ApoJ [55-56]. These oligomeric forms interact with the nerve growth factor receptor (NGF), triggering a toxic mechanism that causes cell death. Moreover, the oligomeric forms bind to Frizzled $(F z)$ receptors, inhibiting the Wnt signaling pathway, and affecting cell proliferation and neuronal differentiation during development of the brain. Furthermore, the inhibition of Wnt signaling by A $\beta$ oligomers causes Tau phosphorylation and the formation of neuro fibrillary tangles, which suggests a Wnt/ $\beta$-catenin toxicity pathway $[35,57]$.

On the other hand, it has also been observed that $A \beta$ oligomers are able to destabilize the plasma membrane, forming pores which alter the normal flow of ions and permitting the entry of extracellular $\mathrm{Ca}^{2+}$ and leading to neuronal death [58-60]. Another mechanism of neuronal receptor-mediated damage is the binding of $\mathrm{A} \beta$ oligomers to $\mathrm{N}$-methyl-D-aspartate (NMDA) type glutamate receptor (NMDAR), which generates altered calcium homeostasis, increased oxidative stress and loss of synapses [61-63].

\subsection{Intracellular $A \beta$}

The presence of intracellular $A \beta$ deposits was first observed by Iqbal et al in 1989 [64]. They identified the presence of intraneuronal $A \beta$, by using an antibody against residues 17-24 of $\mathrm{A} \beta$ peptide in tissue from AD patients. Importantly, they also observed the presence of these immuno-positive deposits in neurons that preferentially contained NFT [64]. The discovery of the coexistence of amyloid and NFT in the same neuron allowed the development of several lines of research that attempt to show how a protein can induce or accelerate the neurodege- 
nerative process [65]. In 1993, Wertkin and et. al. demonstrated that most significantly, the NT2N neurons constitutively generated intracellular A $\beta$ peptide and released it into the culture medium, which demonstrated the intracellular production of $A \beta$ peptide [66]. The presence of mutations in $\mathrm{A} \beta \mathrm{PP}$ (A $\beta$ PPswe), as well as by the duplication of the A $\beta P P$ gene on chromosome 21 (which has been observed in patients with Down syndrome [67-68]) could be favorable to the accumulation of intracellular amyloid. Although there is evidence to support the assertion that amyloid accumulation precedes the formation of extracellular $A \beta$ deposits and the microtubule-related pathology, the link between $A \beta$ and Tau remains unclear [67-69]. It has also been demonstrated that the pathological accumulation of $\mathrm{A} \beta$ and hyperphosphorylation of Tau within synaptic terminals [70] is associated with early changes in MAP2 in neurites and synapses [71]. Finally, the position of soluble oligomers in cellular processes could help to explain their role in the synaptic dysfunction observed in patients with AD [72]. Several reports in the literature have indicated that amyloid can be formed intracellularly [73-75]. Aside from the plasma membrane, it is known that A $\beta P P$ as well as $\beta$ - and $\gamma$-secretase activity are located in the trans-Golgi network, the endoplasmic reticulum, and the endosomal, lysosomal and mitochondrial membranes. $A \beta$ is generated mostly in the sub-cellular region and then secreted through exocytosis. It has been proposed that production of $A \beta 42$ occurs in the endoplasmic reticulum, while the $A \beta 40$ is formed in the trans-Golgi network. It has also been observed that non-neuronal cells produce both $A \beta$ isoforms on the cell surface [73].

Secreted amyloid forms extracellular deposits and may also be able to enter the cell through transporters and membrane receptors such as the acetylcholine receptor, the low-density lipoprotein receptor (LPR), the N-methyl-D-aspartate receptor (NMDAR), and the scavenger receptor for advanced glycation end products (RAGE) [57, 69]. The interaction between amyloid and these receptors can trigger neurotoxicity and neuronal dysfunction.

\subsection{A $\beta$ Toxicity}

The neuronal toxicity mediated by $\mathrm{A} \beta$ has been documented in vitro and in vivo. In vitro studies have demonstrated that the direct administration of $A \beta$ to cell cultures has a neurotoxic effect because it increases oxidative stress levels and apoptosis [76-78]. The accumulation of amyloid also leads to proteasomal dysfunction and the consequent accumulation of damaged, missfolded, and aggregated proteins, including A $\beta$ and Tau [79-81]. The reactive oxygen species (ROS) affect membrane proteins, mitochondrial DNA, lipids, and cytoplasmic proteins, and also contribute to the vascular damage observed in AD patients [57, 61, 82-85]. Oxidative stress has been observed in the early stages of $\mathrm{AD}$ and has been directly associated with $\mathrm{A} \beta$ accumulation. Moreover, $A \beta_{1-42}$, enhanced glutamate toxicity in human cerebral cortical cell cultures and was associated with changes in intracellular $\mathrm{Ca}^{2+}$ levels [86].

Importantly, the alterations in these patients were observed in specific brain areas such as the hippocampus, the entorhinal cortex, the amygdala, the neocortex and some sub-cortical areas, such as the cholinergic neurons in the basal forebrain, the serotonergic neurons of the dorsal raphe nucleus and the noradrenergic neurons of the locus coeruleus. The glutamatergic neurons located in the hippocampus and in the frontal, temporal and parietal cortex are severely affected. As we know, the hippocampus and cortex regions are important for the 
establishment of memory and learning, and so, therefore, the specific loss of glutamatergic neurons could play an important role in the progression of the pathology. Since the 1980's, it has been proposed that Alzheimer's disease may be caused by the over-activity of glutamatergic neurons causing excitotoxic damage in cortical afferent neurons [87-88]. Several studies have shown that $A \beta$ accumulates in certain synapses in micro molar concentrations of $A \beta$, and has the ability to bind to NMDA receptors, thus inducing the internalization and deregulation of the NMDA signaling pathway [63, 89-91].

\section{Glutamatergic system}

\subsection{Glutamate}

Glutamate is a nonessential amino acid that does not cross the blood-brain barrier (BBB), and is produced primarily by neurons and glial cells from local precursors derived from glucose and $\alpha$-ketoglutarate. Glutamate participates in balance with GABA to modulate the activity of GABAergic and glutamatergic neurons [92]. The majority of excitatory neurons in the CNS are glutamatergic; moreover, it is estimated that over half of nerve-endings release glutamate. Presynaptic depolarization promotes vesicles to release their contents of glutamate into the synapses through exocytosis, where upon the released glutamate binds to post-synaptic ionotropic receptors, stimulating an influx of cations which depolarizes the post-synaptic cell [93]. To prevent over-stimulation, glutamate is removed by astrocytes and converted to Lglutamine through the action of glutamine synthetase, which is released to the extracellular fluid taken up by neurons. Glutamine, normally found in the extracellular space, is, unlike glutamate, a non-toxic molecule and lacks the ability to activate glutamate receptors. The glutamine transferred back to the neuron is recycled by phosphate-activated glutaminase and, once again, forms L-glutamate, which is taken by vesicular transporters into synaptic vesicles to be available for use in the excitatory neurotransmission [93-96]. This trafficking of glutamate and glutamine between astrocytes and neurons is the primary route by which glutamate may be recycled (glutamine-glutamate cycle). The removal of this neurotransmitter from the synaptic cleft is carried out through high-affinity transporters. These transport proteins are the only existing mechanism for extracellular glutamate removal, and are of vital importance in maintaining low and non-toxic concentrations of this neurotransmitter [94]. Both neurons and glial cells express glutamate transporters. Glutamate taken up by cells may be used for metabolic purposes (protein synthesis, energy metabolism, ammonia fixation) or be reused as a neurotransmitter [94]. It is important to clarify that glutamate is not necessarily derived from glutamine nor it is necessarily converted to glutamine by astrocytes, nor does glutamine necessarily acts as a precursor to glutamate. While the mechanisms involved and the resulting metabolites are more complex, they are not mentioned in this chapter.

Glutamate is the major excitatory neurotransmitter in the CNS (approximately 8-10 $\mathrm{mM} / \mathrm{kg}$ ), and is found in more than $80 \%$ of all neurons [92, 97-99]. It is involved in most normal brain function, especially in the cortical and hippocampal regions, which deal with cognition, memory and learning [100] among other functions. Glutamate also plays a major role in the 
development of the central nervous system, as well as synapse induction and elimination, cell migration, differentiation and death [101-102]. Most of the glutamate in the brain is located intracellularly inside nerve terminals and only a tiny fraction of this glutamate is normally present outside or between the cells [103-105]. The extracellular elevation of glutamate causes alterations in the glutamate-mediated neurotransmission, activating receptors and inducing the depolarization of neurons which in turn triggers a sequence of intracellular events that conclude in $\mathrm{Ca}^{2+}$ and $\mathrm{Na}^{2+}$ influx. This leads to the exocytosis of glutamate and ultimately cell death, which correlates with the loss of memory function and learning ability in AD patients [106-107]. Recently it has been shown that there is a close correlation between reduced glutamatergic presynaptic button density and cognitive deficits. A study of brain tissue from subjects with no cognitive impairment, mild cognitive impairment, or mild/severe-stage Alzheimer's disease; demonstrated that glutamatergic synaptic remodeling, presents a pattern- dependent pathology, according to disease progression by comparing the mini mental status examination scores of healthy individuals to those of individuals with mild or severe Alzheimer's disease [99, 108] (figure 1).

Glutamate excitotoxicity has also been implicated in other neurodegenerative diseases such as Huntington's disease, epilepsy, ischemia, and trauma [109-111]. In this sense, it is crucial to maintain adequate extracellular levels of glutamate, as it is continuously released from the cells and must therefore be continually removed from the extracellular fluid [93-94, 105]. It has been documented that glutamatergic neurotransmission in neocortical regions and the hippocampus is severely disrupted in Alzheimer's disease. So far, it is unknown whether molecular abnormalities observed in patients are a cause or a consequence of other changes that allow the development of neurodegeneration. Another proposed hypothesis is that alterations in the expression of neurotransmitter transporters could contribute to neurotransmission imbalances in the AD brain [112].

\subsection{Glutamate transporters}

Under normal conditions, the low concentration of glutamate into the extracellular space is regulated by specific transporters, localized in both nerve endings and surrounding glial cells. This transport system prevents cell damage generated by excessive activation of glutamate receptors [105, 112-113]. There are two glutamate transport systems: the Vesicular GluTs (VGLUT) and the Excitatory Amino Acid Transporters (EAAT) located in the plasma membrane. The VGLUTs are crucial for the storage of glutamate in synaptic vesicles. When a neuron is depolarized, glutamate is released into the synaptic cleft where it binds glutamate receptors to pre and post-synaptic neurons. There are three isoforms; VGLUT1, VGLUT2, VGLUT3. The transport of glutamate into secretory vesicles is highly dependent on $\mathrm{Cl}^{-}$[114]. This anion stimulates glutamate transport, but is inhibitory at higher concentrations. This process is driven by an electrochemical gradient of $\mathrm{H}^{+}$established by V-ATPase, which, together with the VGLUT activity, affect vesicular glutamate content and subsequently the glutamatergic signaling [115].

Studies have also identified five different 'high-affinity' glutamate excitatory amino acid (EAATs) transporters (EAAT1, EAAT2, EAAT3, EAAT4 and EAAT5). Residing on postsy- 


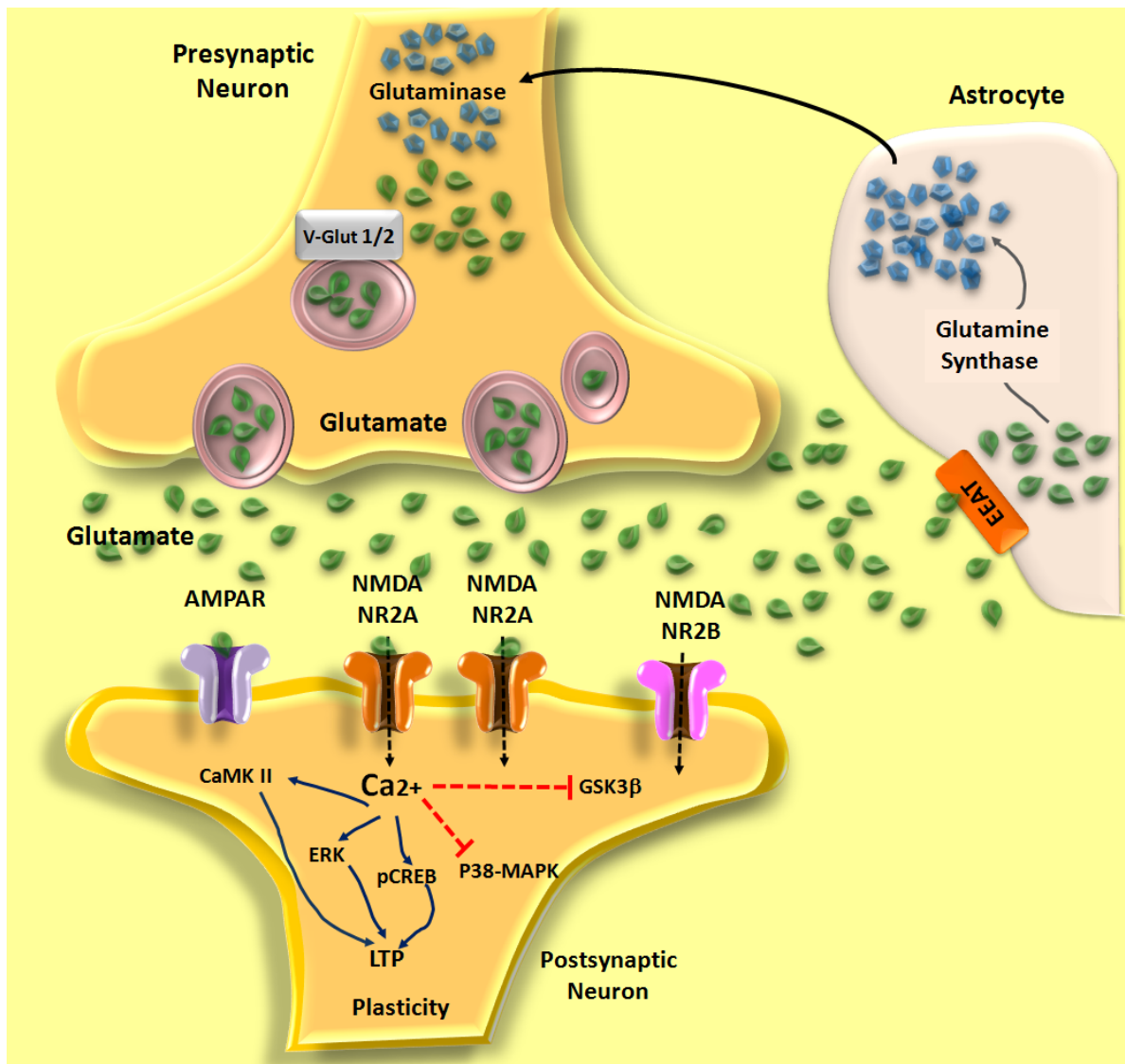

Figure 1. Glutamatergic Transmission in Normal Brain. Glutamate released from presynaptic terminals acts through the activation of glutamate receptors located at the postsynaptic terminal. The interaction between glutamate and NMDA receptor favors the activation of several metabolic pathways such as CaMK, ERK, and CREB, which are responsible for anabolic activation with subsequent activation of long-term potentiation (LTP) mechanisms. Glutamate excess is transported via the EAAT into astrocytes, where is transformed to glutamine by the glutamine synthase. Subsequently, glutamine it is converted into glutamate by glutaminase and packaged into vesicles through specific transporters (VGlut). VGlut (vesicular glutamate transporter); EAAT (excitatory amino acid transporter); NMDANR2A (Nmethyl-D-aspartate NR2A subunit); NMDANR2B (N-methyl- D-aspartate NR2B subunit); ERK (extracellular signalrelated kinase); CaMKII (calcium calmodulin-dependent kinase II); pCREB (phosphorylated cyclic AMP response element binding protein); GSK3b (glycogen synthase kinase 3b); p38-MAPK (p38 mitogen-activated protein kinase).

naptic GABAergic neurons, EAATs transport glutamate and serve as a precursor for the synthesis of GABA. These two transporter families differ in many of their functional properties, including substrate specificity and ion requirements [113]. EAATs-mediated glutamate transport is $\mathrm{Na}^{+}$dependent, where, for each transport cycle, one glutamate molecule is transported together with two or three $\mathrm{Na}^{+}$ions and one $\mathrm{H}^{+}$in exchange for one $\mathrm{K}^{+}$ion. These transporters also interact with other proteins at the plasma membrane and are regulated by protein kinases, growth factors and second messengers [116-117]. Alterations in this regulatory 
system as well as genetic mutation in the transporters and enzymes involved in the glutamate metabolism can lead to excitotoxic damage due to an excessive release of glutamate, which in turn can lead to neuronal death.

\subsection{Glutamate receptors}

Glutamate-mediated neurotransmission occurs through specific receptors. There are 2 families of glutamate receptors located on the plasma membrane of the neurons: ionotropic (iGluR) glutamate receptors, which act as ion channels, and metabotropic (mGluR) glutamate receptors which are linked to the intracellular second messenger systems [92, 99, 118-119].

The iGluR family is divided into three kinds of receptors, depending on their permeability to different cations. NMDA receptors (NR1, NR2A-D and NR3A-B) are predominantly $\mathrm{Ca}^{2+}$ ion permeable, whereas $\alpha$-amino-3-hydroxy-5-methyl-4-isoxazolepropionic acid (AMPA; GluR1-4) and Kainate (KA; GluR5-7, KA1-2) receptors are predominantly permeable to $\mathrm{Na}^{+}$and $\mathrm{K}^{+}$ions $[99,120]$. Each of these receptors is composed of four subunits, and variations in the expression of each subunit have different types of response in the receptor function [92, 119]. AMPA receptors have a lower affinity for Glutamate than NMDA receptors, and are responsible for an initial excitatory potential when Glutamate is present in the synapse [92]. Kainate receptors play a role in synaptic neurotransmission, but the exact nature of this role is unclear [119].

NMDA and AMPA receptors are present in most of the synapses in mammalian brains (approximately 70\%). This type of receptor is preferentially localized in the cerebral cortex, hippocampus, amygdala, striatum, and septum. The specific location of these receptors is of great importance, since glutamatergic signaling has a very important role in both the plasticity and excitotoxicity processes, and, therefore, changes in their function lead to the development of neurodegenerative processes.

The NMDA receptor is the most important and studied ionotropic receptor to date, and participates in several functions such as synaptogenesis, synaptic plasticity, learning and memory, as well as in the pathogenesis of several central nervous system disorders [121-123]. Calcium influx through the NMDA receptor is capable of modulating physiological and pathological conditions in the neuron. The increase in intracellular $\mathrm{Ca}^{2+}$ concentration triggers a cascade of events that dramatically modifies synaptic efficacy and neuronal morphology. Functional NMDA receptors are heterotetrameric complexes composed of different subunits (GluN1, GluN2A-D, GluN3A-B). Typically, each NMDAR comprises two obligatory GluN1 subunits and two GluN2 subunits, which can a form a dimer themselves, or alternatively one GluN2 can combine with one GluN3 subunit to do the same [121, 123-124]. GluN1 occurs as eight distinct isoforms encoded by a single gene [125]. The functional significance of the differential expression of GluN1 isoforms is not clear. GluN2 and GluN3 also exist in several alternatively spliced forms, although the functional differences between them are complex. There are four genes encoding GluN2 subunits and each has a unique spatiotemporal profile. In addition, GluN2A and GluN2B are expressed primarily in the cortex and hippocampus and differ in their kinetic properties, developmental expression pattern, subcellular localization and trafficking regulation. GluN3 subunits also display differential expression patterns, with 
GluN3A peaking in early postnatal life and GluN3B increasing throughout development [123]. Finally, although receptor subunits have structural similarities, the composition of the different receptor subtypes confer distinct functional and biophysical properties that are reflected in the ion permeability, protein interactions and membrane localization (synaptic or extrasynaptic). They may also have different roles in modulating synaptic plasticity and development of pathologies [122-123]. In fact, the expression of individual subunits is highly dependent on brain area and developmental stage, thus, alterations in the expression of each subunit can lead to a pathological condition which may be reflected in the development of neurodegenerative diseases.

\subsection{Glutamate/NMDAR: Role in learning and memory}

In the CNS, it is known that the hippocampus is closely related to learning and memory, and has a very high density of glutamate receptors, particularly the NMDA-type, which are significantly involved in this type of neuronal plasticity. Glutamate is essential for the establishment of new neural networks, forming memory and learning through a process known as long-term potentiation (LTP) or long-term depression (LTD) of synaptic strength, which occurs upon activation of NMDA receptors.

NMDA receptors are characterized by their high $\mathrm{Ca}^{2+}$ ions' permeability, their voltage dependent blockade by $\mathrm{Mg} 2+$ ions, and their slower gating kinetics. At rest, the NMDA receptor is blocked by $\mathrm{Mg}^{2+}$, while prolonged activation by the presence of glutamate allows the release of the $\mathrm{Mg}^{2+}$, opening the NMDA receptor and allowing the $\mathrm{Ca}^{2+}$ ions to freely enter into postsynaptic neuron. Calcium entering through the NMDA receptors activates CaMKII, PKA, PKC and mitogen-activated protein kinase (MAPK), and protein phosphatases. Activated CaMKII phosphorylates the AMPA-type glutamate receptor 1 (GluR1) subunit, which, in turn, promotes synaptic incorporation of GluR1-containing AMPARs, thereby increasing AMPAR number and channel conductance $[107,121,126]$. The fundamental role of the NMDAreceptor system in the establishment of learning and memory has been demonstrated in various animal models [127-131]. However, pharmacological studies and the manipulation of experimental models have shown that, although this system is important in memory induction, it does not participate in the maintenance of memory [132-135] (figure 1).

These features make NMDA receptors quite suitable for mediating plastic changes in the brain, such as learning. However, they may also contribute to the excitotoxicity processes produced by a massive influx of $\mathrm{Ca}^{2+}$. Under these conditions, the continuous presence of glutamate induces constant activation of the NMDA receptor, and the ensuing massive influx of $\mathrm{Ca}^{2+}$ may trigger a cascade of events leading to neuronal injury and death[136]. Chronic depolarization of the membrane on vulnerable neurons, as observed in AD patients, is accompanied by other disorders such as neuronal oxidative stress, mitochondrial damage, and inflammation, and the presence of amyloid beta and possibly hyperphosphorylated-tau, which may eventually increase the sensitivity of the glutamatergic system and result in neuronal dysfunction and cell death [97, 106-107]. 


\subsection{Neurotoxicity of $A \beta$ : Synaptic dysfunction in AD}

Aside from the above toxic effects, it is known that amyloid has the ability to inhibit normal function of the glutamatergic system. It can also interact with glutamine synthetase (GS) to induce the inactivation of the enzyme [137], chronically depolarize neurons through its action on the metabotropic glutamate receptor 1 [138], and partially relieve the voltage-dependent $\mathrm{Mg}^{2+}$ block of NMDA receptors, which allows the continuous entry of calcium into neurons by altering the homeostasis and thus causing cell death. This also causes that neurons to express NMDA receptors selectively and become vulnerable to glutamatergic stimulation. In AD patients, it has been observed that glutamatergic transmission is severely affected by neurons in the cortex and hippocampus (Figure 2).

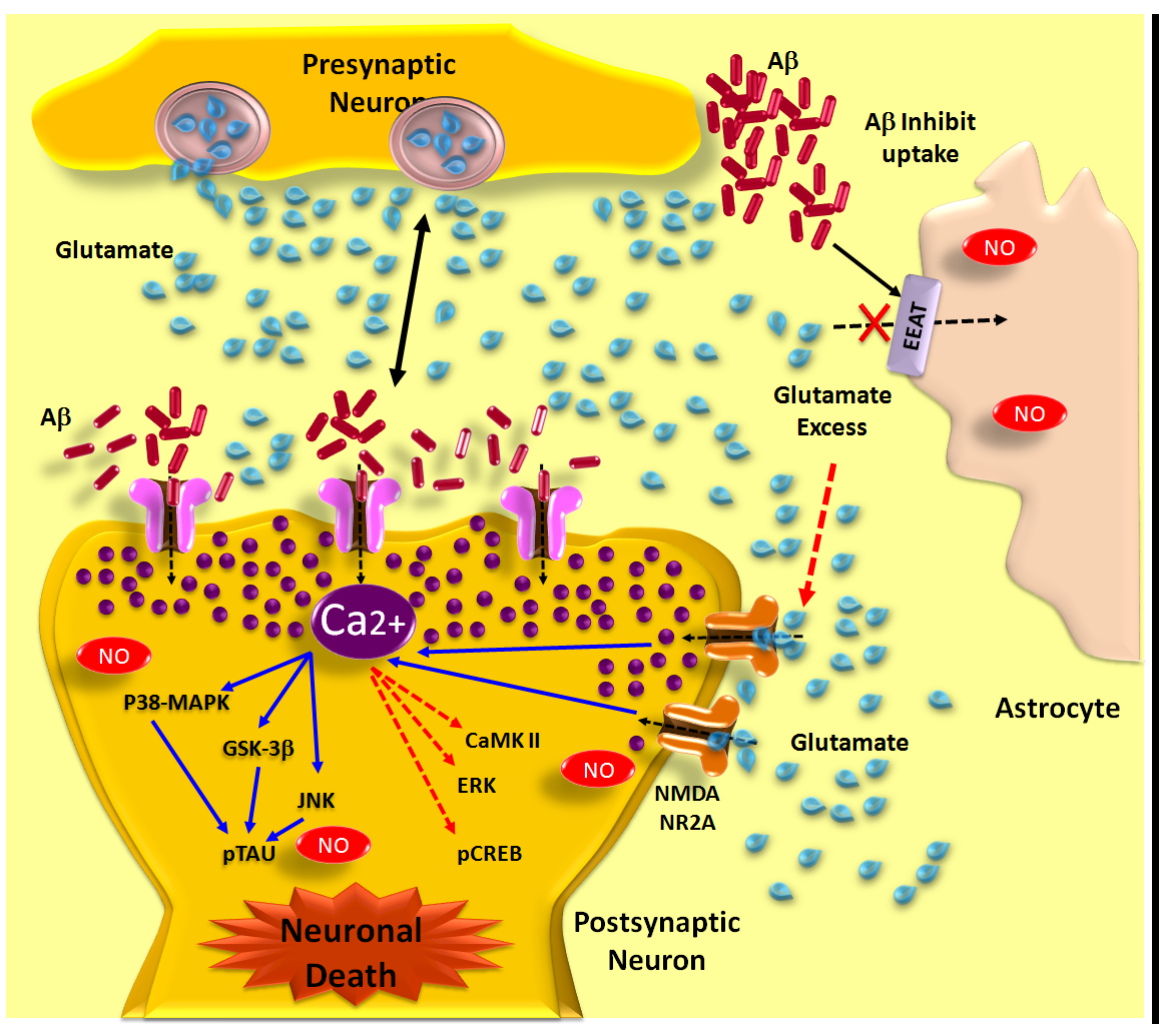

Figure 2. Glutamatergic transmission in Alzheimer's disease. A $\beta$ oligomers enhance the pre-synaptic release of glutamate together with the simultaneous blockade of glutamate uptake by astrocytes through glutamate transporters (EAAT), due to this, glutamate concentration in synaptic cleft increases. In addition, A $\beta$ form complexes with alpha7nicotinic receptors, increasing levels of glutamate release. Activation of NMDA receptors increases the influx of calcium and activates signaling pathways responsible for neuronal shrinkage and synaptic loss (p38-MbAPK, GSK-3b, JNK), leading to Tau phosphorylation and neuronal death. Finally, there is an inhibition of the survival pathways (CAMK II, ERK, pCREB). 
Neurochemical analysis performed on tissue from patients with AD revealed deficits in numerous neurotransmitters. Early symptoms appear to correlate with dysfunction of cholinergic and glutamatergic synapses. Furthermore, morphometric studies of temporal and frontal cortical biopsies from $\mathrm{AD}$ have revealed that there is a $25-30 \%$ decrease in the density of synapses. In the same way, it has been observed that the degree of cognitive impairment observed correlates with changes in the protein synaptophysin in the hippocampus. In fact, it has also been shown that the presence of soluble amyloid correlates with cognitive deficits and synapse loss [139-140].

In 2005, Kokubo et al investigated the ultrastructural localization of soluble A $\beta$ oligomers in human brain tissue. They used post-embedding immunoelectron microscopy (IEM) [72] and an antibody that specifically recognizes soluble oligomers [141]. The results showed that approximately $80 \%$ of oligomers are found in active cellular processes. In addition, oligomers were found in both the presynaptic active zone and in postsynaptic densities, and their presence may be related to synaptic dysfunction [72]. This might suggest that the A $\beta$ oligomers are released from the presynaptic site into extracellular space or are synaptically transported from neuron to neuron. These results agree with the hypothesis that the oligomerization of A $\beta$ begins intracellularly [50]. The amyloid that is released from presynaptic terminals and not degraded efficiently accumulates in extracellular deposits and could serve as a seed to induce further accumulation of $A \beta$ aggregates that culminates in the formation of neuritic plaques [142-143]. Neprilysin is an enzyme which is located in the presynaptic sites and participates in the $\mathrm{A} \beta$ clearance. In AD, Neprilysin is decreased and may contribute to AD pathogenesis increasing the amyloid levels in the presynaptic sites [144-145]. This was demonstrated in a transgenic mouse model that expressed low levels of APP and had one or both NEP genes silenced. The analysis of the brains and plasma in young and old mice showed elevated levels of human $A \beta 1-40$ and $A \beta 1-42$, an increase in $A \beta$ dimer concentration, and a markedly increased hippocampal amyloid plaque burden, and led to development of severe amyloid angiopathy, supporting the hypothesis that primary defects in $A \beta$ clearance can cause or contribute to AD pathogenesis [146].

In 2012, Koffie et al analyzed more than 50,000 synapses in 11 AD brains and 5 control subjects, and found that the synapse loss directly correlated with the presence of oligomeric amyloid. This was confirmed by the use of specific antibodies, such as NAB61, which recognizes oligomeric $A \beta$, and the R1282 antibody which recognizes all conformations of amyloid and the 82E1 antibody [147]. Extensive neuronal loss is another important feature in the Alzheimer's pathology and, is observed as being restricted to the cell bodies and dendrites of glutamatergic neurons located in layers III and IV of the neocortex and the glutamatergically innervated cortical and hippocampal neurons [38, 148].

The mechanism by which $\mathrm{A} \beta$ oligomers induce synaptic dysfunction remains unknown; however, it has been proposed that this alteration in synaptic transmission may be performed through non-excitotoxic glutamatergic mechanisms [149]. In this way, the accumulation of $\mathrm{A} \beta$ oligomers in synaptic components, especially in the axon terminal, results in synaptic and cognitive dysfunction seen in AD [72]. 


\subsection{Animal models in AD and synaptic dysfunction}

Several studies have shown that amyloid oligomers - both synthetic [150] and those isolated from the brains of patients [63] - have the ability to induce synaptic alterations in neuronal cultures and organotypic hippocampal slice cultures. The transgenic mice models that express different APP mutated forms show extensive neuritic dystrophy and loss of synapses, important features that suggest a neurodegenerative process. In this way, it has been suggested that $\mathrm{A} \beta$ oligomers could modulate both pre and post-synaptic structures and functions in a dose and assembly-dependent manner [151-152]. The results indicate that protofibrils and oligomeric forms of $\mathrm{A} \beta$ most likely generate neuronal death through a nucleation-dependent process rather than acting as direct neurotoxic ligands [153]. In 2008, Shankar and colleagues showed that the presence of $A \beta$ oligomers in slice cultures blocked the LTP, while NP-derived aggregates had no effect unless they were treated with formic acid. The oligomers potently inhibited long-term potentiation (LTP), enhanced long-term depression (LTD), and reduced dendritic spine density in a normal rodent hippocampus [154].

Animal models overexpressing hA $\beta$ PP protein also show a decrease in synaptophysin-positive presynaptic terminals, approximately $30 \%$ less than that observed in non-transgenic mice. Is important to note that these decreases in presynaptic terminals are dependent on soluble amyloid levels rather than on plaques per se [63, 152, 154-156], which would also explain the cognitive deficits observed. In a triple transgenic mice model which presented PS1(M146V), $\mathrm{APP}(\mathrm{Swe})$, and tau(P301L) transgenes (3xTg-AD), it was possible to show that the intraneuronal amyloid deposition correlates with the cognitive deficits observed in these mice. At six months, the 3xTg-AD mice showed a profound LTP deficit and intraneuronal A $\beta$ accumulation occurring within pyramidal neurons. This cognitive deficit occurs before the accumulation of extracellular amyloid aggregates, suggesting that cognitive impairment occurs before the formation of neuritic plaques [157-160]. The synaptic dysfunction, including LTP deficits and cognitive alteration manifests in an age-related manner [157].

Moreover, it has also been observed that $\mathrm{A} \beta$ oligomers bind to high-affinity cell-surface receptors (cellular prion protein or $\operatorname{Pr} \mathrm{P}(\mathrm{C})$ and block hippocampal long-term potentiation and dendritic spine retraction from pyramidal cells at nanomolar concentrations of oligomers. Anti-PrP antibodies prevent the $\mathrm{A} \beta$-oligomer from binding to $\mathrm{PrPC}$ and rescue synaptic plasticity in hippocampal slices from oligomeric $A \beta$ [161]. Other studies also have shown that $\mathrm{A} \beta /$ PrPC interaction leads to activation of Fyn kinase. PrPC /Fyn signaling yields phosphorylation of the NR2B subunit of NMDA receptors, which is coupled with an initial increase and then a loss of surface NMDA-receptors. Thus, A $\beta$ generates changes in GluR function and dendritic spine anatomy. Additionally, Fyn activation might suggest correlation with Tau pathology and the epileptiform phenotype observed in some patients with AD [162]. In this sense, it has been reported that oligomers of A $\beta$ lead the activation of AMPK. The increased intracellular $\mathrm{Ca}^{2+}$ induced by membrane depolarization or NMDA receptor activation triggers AMP-activated kinase (AMPK) activation in a CAMKK2-dependent manner. CAMKK2 or AMPK overactivation is sufficient to induce dendritic spine loss [163]. The roles of AMPK in the pathogenesis of $\mathrm{AD}$ include $\beta$-amyloid protein $(\mathrm{A} \beta)$ generation and tau phosphorylation [164]. AMPK phosphorylates Tau in S262, while expression of Tau S262A inhibits the synap- 
totoxic effects of A $\beta 42$ oligomers, which suggests that the CAMKK2-AMPK-Tau pathway could be a critical mediator of the synaptotoxic effects of A $\beta 42$ oligomers [163]

Dendritic spines are certainly the sites with more excitatory synapses, and their loss correlates with the cognitive impairment observed in Alzheimer's patients [165]. A large body of evidence suggests that amyloid oligomers may cause loss of dendritic spines [47, 166-172]. The exposure of cultured pyramidal neurons to $A \beta$ oligomers showed decreased synaptic activity and a decrease in the density of dendritic spines [154]. Multiphoton imaging of GFP-labeled neurons in living Tg2576 APP mice showed disrupted neurite trajectories and reductions in dendritic spine density compared with age-matched control mice. Spine loss is most pronounced near plaques, indicating focal toxicity and also that the decrease in the density of dendritic spines may contribute to the altered neuronal function observed in these mice [166]. It has also been found that $\mathrm{A} \beta$ trimmers fully inhibit LTP, whereas dimers and tetramers have an intermediate potency and support the hypothesis that diffusible oligomers of $A \beta$ initiate a synaptic dysfunction that may be an early event in $\mathrm{AD}$ [173]. It is known that the presence of oligomers of $A \beta$ induces the loss of synapses, although little is known whether synapse loss precedes or follows plaque formation. In 2012, Bittner et al conducted an in vivo study using two-photon microscopy through a cranial window in double transgenic APPPS mice. Using this technique, they observed the manner in which the amyloid is deposited to form neuritic plaques and determined the loss of dendritic spines in the vicinity of these deposits. They found that the rate of dendritic spine loss in proximity to plaques is the same in both young and older animals. The plaque size only increases in young animals, while spine loss persists even many months after the initial appearance of the plaque. Finally, they found that spine loss occurs, with a significant time delay, after the birth of new plaques, and persists in the vicinity of amyloid plaques over many months [168].

A key aspect that determines the functionality of dendritic spines is their morphology. It is known that Calcineurin $(\mathrm{CaN})$ activation is critically involved in regulating both the morphology of the spines in response to oligomeric $A \beta$, and the synaptic plasticity in normal memory. When adding oligomers derived from Tg2576 murine transgenic neurons or human $\mathrm{AD}$ brains to wild-type murine primary cortical neurons, $\mathrm{CaN}$ activation in spines was observed and led to rapid but reversible morphological changes in spines and postsynaptic proteins, suggesting that Calcineurin might have an important role in regulating the synaptic alterations associated with Alzheimer's disease [174]. Finally, it has been shown that APP has an important role in regulating synaptic and structure function. Analysis of dendritic spines in the primary cultures of hippocampal neurons and the CA1 neurons of hippocampi of APP ${ }^{-/}$mice showed a significant decrease in spine density (35\%), compared to control cultures. This spine loss was partially restored with $\mathrm{sAPP} \alpha$-conditioned medium. These abnormalities in neuronal morphology were also accompanied by a reduction in long-term potentiation. These results suggest that $\mathrm{SAPP} \alpha$ is necessary for the maintenance of dendritic integrity in the hippocampus [172].

The changes in dendritic spines observed in various diseases impact heavily on synapse function and circuit-level connectivity in the form of altered connectivity or changes in connection strength [175]. Changes in the number and morphology of the spines can start a cascade of symptoms and effects that lead to the pathological changes observed in Alzheimer's disease. 


\subsection{A $\beta$ and synaptic plasticity}

Although for many years the theory has been maintained that beta amyloid deposits are the main factor in AD pathology, recent years have seen an increase in the evidence pointing to the fact that its accumulation in certain brain regions may participate importantly in memory and cognition [176]. This dual concept of amyloid, where, at low doses it can positively stimulate the normal physiological processes of the cells, and at high doses it can cause toxic effects has also been observed in a very large number of molecules. This idea has been strongly supported by the observation that APP knock-out mice show long-term potentiation (LTP) and memory impairment [44, 177]. Glutamate, the main excitatory neurotransmitter is undoubtedly another example, as it is known that at low doses, it has the ability to stimulate synaptic plasticity and memory [178], while at high doses it is toxic and favors the development of several neurodegenerative diseases.

We have already mentioned that the amyloid is generated the proteolytic processing of APP through the action of $\beta$-and $\gamma$-secretases. In recent years, it has been reported that these enzymes are involved in memory and synaptic plasticity. In 2004, Saura and colleagues developed conditional double knockout mice lacking the expression of both presenilins in the postnatal forebrain. The results showed impairments in hippocampal memory and synaptic plasticity. These alterations are associated with decreases in NMDA receptor-mediated responses and the synaptic levels of NMDA receptors and $\alpha$ CaMKII. Also, a decrease was observed in the expression of CBP and CREB/CBP target genes, such as $c$-fos and BDNF, while, increased levels of the Cdk5 activator p25 and hyperphosphorylated Tau were also observed. Finally, these mice develop a process of neurodegeneration, which increases with age. These results indicate that the inhibition of presenilin could accelerate memory loss and neurodegeneration [179]. Other trials have suggested that synaptic plasticity and memory depend on BACE1-mediated APP processing, which may facilitate memory and synaptic plasticity [180]. In the same way, BACE1 null mice exhibit alterations in hippocampal synaptic plasticity as well as in their performance in tests of cognition and emotion [181]. Recently it has been suggested that concentrations of picomolar amyloid are capable of inducing synaptic plasticity and memory in the hippocampus, and that the exposure of amyloid to Aß did not affect the NMDA receptor. The action mechanism of picomolar $\mathrm{A} \beta 42$ on synaptic plasticity and memory involves $\alpha 7$-nicotinic acetylcholine receptors [44], suggesting that A $\beta 42$ may be an important modulator of synaptic plasticity and memory in the normal brain. Furthermore it has been observed that many of the effects on amyloid NMDA receptors can be blocked by antagonists of this receptor.

\section{Glutamatergic system-targeted treatment in Alzheimer's disease: Focus on memantine}

A $\beta$ peptide is able to interact with a whole variety of proteins [97], and this interaction may cause dysfunction of the protein to which $A \beta$ is binding. One group of proteins with which $\mathrm{A} \beta$ is able to interact is the glutamatergic NMDA receptors. Texidó et al. [182] showed that the $\mathrm{A} \beta$ peptide directly binds and activates NMDA receptors expressed in Xenopus laevis oocytes, 
thereby causing an increase in cytosolic calcium concentration. These results are coincident with previous results by McDermott et al. [183], who reported increased calcium intracellular concentration in spinal cord mouse neuron cultures, after adding NMDA. Cytosolic calcium overload causes mitochondrial dysfunction and leads to an increase in ROS production, which in turn generates oxidative stress and leads to cell death [184]. For these reasons, the idea was born that NMDAR antagonists could be a promising therapeutic target in AD treatment.

Among all the known NMDAR antagonists, the most widely studied and used in the treatment of $\mathrm{AD}$ is the molecule known as memantine. Memantine (1-amine-3, 5, dimethyladamantane) was first synthesized in 1963 [185]. The drug is a derivative of amantadine, an antiviral used in influenza treatment. Like amantadine, memantine has a three ring structure, with an amine group and two methyl groups [186]. Memantine NMDAR antagonist properties remained unknown until Kornhuber et al. [187] reported that memantine had the same properties and same binding site of the well known NMDAR antagonist MK-801. Chen and Lipton [186] observed that memantine affinity towards NMDA receptors was sensitive to NMDA concentration, leading to the conclusion that memantine NMDA receptor antagonism is uncompetitive. It is this uncompetitivity and the fact that his binding is voltage-dependent which makes memantine an effective and safe therapeutic agent. For memantine to be able to exhibit its inhibitory activity, the receptor channel must be in an open state. Memantine blocks NMDAR activity by entering and binding to the cation pore, thus preventing cation flux and inhibiting functional NMDAR activity. Memantine binding to the receptor is voltage-dependant, in such a way that it leaves the channel pore in depolarization conditions, i.e. during excitatory postsynaptic potential, this way allowing synaptic activity to be maintained [188].

Memantine disease-modifying efficacy and safety has been proven in many studies. Most assays using a variety of AD animal models have lead to promising results. Minkeviciene et al. [189] showed that a 4 week oral treatment with memantine (via drinking water) improved the performance in the Morris water maze of mice carrying both a human APP transgene with the Swedish mutation and a human PS1 transgene with the A246E mutation, when compared with placebo-treated mice. In fact, this study showed that memantine-treated transgenic mice performed well in the water maze as well as WT mice, thus revealing a complete rescue of cognitive function due to memantine. Surprisingly, a later study [190] using this same mouse model did not find an effect of memantine treatment on performance in the Morris water maze, but memantine-treated mice performed better in a left-right discrimination task when compared with placebo-treated mice. Another study [191], which used heterozygous APP23 mice (mice carrying one copy of a human APP transgene with the Swedish mutation), reported an increase in spatial accuracy of memantine-treated mice in the Morris water maze, as measured by the time mice spent in the target quadrant of the maze. However, in this study, memantine failed to decrease escape latency (time that takes to mice to reach the target platform of the maze). Martínez-Coria et al. [192], using 3x-TgAD mice (mice that express simultaneously a human APP transgene carrying the Swedish mutation, a PS1 gene carrying the M146V mutation and a human tau transgene carrying a P301L mutation), showed that treatment with memantine caused a significant improvement in mice performance in the 
Morris water maze, in an object recognition task and in a passive avoidance task, showing that memantine has an effect on different types of memory.

In contrast, few studies have failed in obtaining a significant cognitive function improvement after memantine treatment. Dong et al. [193], using Tg2576 mice (which also express the Swedish mutation), did not find any treatment effect in a conditioned fear experiment after six months of daily memantine administration. Interestingly, histological analysis revealed that the memantine-treated group exhibited less $\mathrm{A} \beta$ plaque deposition, less axonal degeneration and increased synaptic density, when compared with the placebo-treated group.

Because memantine appeared to be effective and safe in animal model assays, clinical trials soon began to be developed. In general, results from these trials showed a modest effect increasing the preservation of cognitive function. Rive et al. [194] classified a group of 252 AD patients in "autonomous" or "dependant" according to their punctuation by the ADCS-ADL (Alzheimer's Disease Cooperative Study-Activities of Daily Living) scale and found that, after a 28-week treatment with memantine or placebo, memantine-treated patients had 3 times more probability of remaining autonomous than placebo-treated patients. Peskind et al. [195] measured the outcomes of 403 AD patients for the ADAS-cog (Alzheimer's Disease Assessment Scale-cognitive subscale), the CIBIC-Plus (Clinician's Interview-Based Impression of Change-Plus caregiver input) scale and the NPI (Neuro-Psychiatric Inventory) scale. Measurements were taken at the beginning of the study and after 24 weeks of memantine or placebo treatment. Results showed that memantine-treated patients exhibited better performance in all of these scales, when compared to placebo treated patients. Another study [196] showed that after 24 weeks of treatment with memantine or placebo, memantine-treated AD patients exhibited significantly slower cognitive decline compared with those treated with placebo, as measured by the SIB (Severe Impairment Battery). Memantine also showed to be moderately effective in the improvement of semantic memory. The study by Ferris et al. [197] found a significant amelioration of language impairment (assessed by the language subscale of the SIB) in AD patients after 28 weeks of memantine treatment. Another study [18] followed 295 AD patients receiving memantine or placebo during 52 weeks. Their results show that memantinetreated patients scored 1.2 points higher in the MMSE (Mini-Mental State Examination) than placebo treated patients.

\section{Conclusion}

All the aforementioned results point out that memantine is a safe disease-modifying drug to use in AD treatment, and its effectiveness has turned out to be slight, but significant, and comparable to that of other AD treatment drugs, such as cholinesterase inhibitors. Clinical trials in order to assess the effectiveness of combined treatment of memantine with other drugs are currently being implemented.

Finally, studies reported in the literature suggest that $A \beta$, the glutamatergic system, and in particular NMDA receptors have a major role in the processes of learning and memory. Synaptic plasticity can be regulated positively or negatively, depending on the levels and 
degrees of amyloid oligomerization. The negative effect of these oligomeric forms may be reversed by the presence of NMDA receptor antagonists. In this regard, it has been reported that the noncompetitive antagonist memantine is able to block the "pathological" receptor activation exerted by these oligomers. In this view, an early pharmacological treatment with memantine, or even a memantine associated treatment combined with AChE inhibitors, might represent a very good option for the treatment of patients with AD.

\section{Author details}

Victoria Campos-Peña ${ }^{1}$ and Marco Antonio Meraz-Ríos ${ }^{1 *}$

*Address all correspondence to: mmeraz@cinvestav.mx

1 Laboratorio Experimental de Enfermedades Neurodegenerativas, Instituto Nacional de Neurología y Neurocirugía, Manuel Velasco Suárez, México City, México

Departamento de Biomedicina Molecular, Centro de Investigación y de Estudios Avanzados del IPN, (CINVESTAV-IPN), México City, México

\section{References}

[1] Borchelt, D.R., et al., Familial Alzheimer's disease-linked presenilin 1 variants elevate Abeta1-42/1-40 ratio in vitro and in vivo. Neuron, 1996. 17(5): p. 1005-13.

[2] Chartier-Harlin, M.C., et al., Screening for the beta-amyloid precursor protein mutation (APP717: Val----Ile) in extended pedigrees with early onset Alzheimer's disease. Neurosci Lett, 1991. 129(1): p. 134-5.

[3] Duff, K., et al., Increased amyloid-beta42(43) in brains of mice expressing mutant presenilin 1. Nature, 1996. 383(6602): p. 710-3.

[4] Levy-Lahad, E., et al., A familial Alzheimer's disease locus on chromosome 1. Science, 1995. 269(5226): p. 970-3.

[5] Murrell, J., et al., A mutation in the amyloid precursor protein associated with hereditary Alzheimer's disease. Science, 1991. 254(5028): p. 97-9.

[6] Sisodia, S.S., S.H. Kim, and G. Thinakaran, Function and dysfunction of the presenilins. Am J Hum Genet, 1999. 65(1): p. 7-12.

[7] Pigino, G., et al., Alzheimer's presenilin 1 mutations impair kinesin-based axonal transport. J Neurosci, 2003. 23(11): p. 4499-508. 
[8] Sherrington, R., et al., Alzheimer's disease associated with mutations in presenilin 2 is rare and variably penetrant. Hum Mol Genet, 1996. 5(7): p. 985-8.

[9] Sherrington, R., et al., Cloning of a gene bearing missense mutations in early-onset familial Alzheimer's disease. Nature, 1995. 375(6534): p. 754-60.

[10] Kowalska, A., Amyloid precursor protein gene mutations responsible for early-onset autosomal dominant Alzheimer's disease. Folia Neuropathol, 2003. 41(1): p. 35-40.

[11] Corder, E.H., et al., Gene dose of apolipoprotein E type 4 allele and the risk of Alzheimer's disease in late onset families. Science, 1993. 261(5123): p. 921-3.

[12] Schupf, N. and G.H. Sergievsky, Genetic and host factors for dementia in Down's syndrome. Br J Psychiatry, 2002. 180: p. 405-10.

[13] Tang, M.X., et al., Relative risk of Alzheimer disease and age-at-onset distributions, based on APOE genotypes among elderly African Americans, Caucasians, and Hispanics in New York City. Am J Hum Genet, 1996. 58(3): p. 574-84.

[14] Zahs, K.R. and K.H. Ashe, beta-Amyloid oligomers in aging and Alzheimer's disease. Front Aging Neurosci, 2013. 5: p. 28.

[15] Chen, J.H., K.P. Lin, and Y.C. Chen, Risk factors for dementia. J Formos Med Assoc, 2009. 108(10): p. 754-64.

[16] de la Torre, J.C., How do heart disease and stroke become risk factors for Alzheimer's disease? Neurol Res, 2006. 28(6): p. 637-44.

[17] Holscher, C., Diabetes as a risk factor for Alzheimer's disease: insulin signalling impairment in the brain as an alternative model of Alzheimer's disease. Biochem Soc Trans, 2011. 39(4): p. 891-7.

[18] Goedert, M., et al., Cloning and sequencing of the cDNA encoding a core protein of the paired helical filament of Alzheimer disease: identification as the microtubule-associated protein tau. Proc Natl Acad Sci U S A, 1988. 85(11): p. 4051-5.

[19] Jakes, R., et al., Identification of 3- and 4-repeat tau isoforms within the PHF in Alzheimer's disease. EMBO J, 1991. 10(10): p. 2725-9.

[20] Wischik, C.M., et al., Structural characterization of the core of the paired helical filament of Alzheimer disease. Proc Natl Acad Sci U S A, 1988. 85(13): p. 4884-8.

[21] Wischik, C.M., et al., Isolation of a fragment of tau derived from the core of the paired helical filament of Alzheimer disease. Proc Natl Acad Sci U S A, 1988. 85(12): p. 4506-10.

[22] Iversen, L.L., et al., The toxicity in vitro of beta-amyloid protein. Biochem J, 1995. 311 ( Pt 1): p. 1-16.

[23] Glenner, G.G., et al., The amyloid deposits in Alzheimer's disease: their nature and pathogenesis. Appl Pathol, 1984. 2(6): p. 357-69. 
[24] Selkoe, D.J., Alzheimer's disease: a central role for amyloid. J Neuropathol Exp Neurol, 1994. 53(5): p. 438-47.

[25] Kang, J., et al., The precursor of Alzheimer's disease amyloid A4 protein resembles a cell-surface receptor. Nature, 1987. 325(6106): p. 733-6.

[26] Samuel, W., et al., Hippocampal connectivity and Alzheimer's dementia: effects of synapse loss and tangle frequency in a two-component model. Neurology, 1994. 44(11): p. 2081-8.

[27] Arriagada, P.V., et al., Neurofibrillary tangles but not senile plaques parallel duration and severity of Alzheimer's disease. Neurology, 1992. 42(3 Pt 1): p. 631-9.

[28] Giannakopoulos, P., et al., Tangle and neuron numbers, but not amyloid load, predict cognitive status in Alzheimer's disease. Neurology, 2003. 60(9): p. 1495-500.

[29] Serrano-Pozo, A., et al., Neuropathological alterations in Alzheimer disease. Cold Spring Harb Perspect Med, 2011. 1(1): p. a006189.

[30] Puzzo, D. and O. Arancio, Fibrillar beta-amyloid impairs the late phase of long term potentiation. Curr Alzheimer Res, 2006. 3(3): p. 179-83.

[31] Puzzo, D., A. Palmeri, and O. Arancio, Involvement of the nitric oxide pathway in synaptic dysfunction following amyloid elevation in Alzheimer's disease. Rev Neurosci, 2006. 17(5): p. 497-523.

[32] Prasansuklab, A. and T. Tencomnao, Amyloidosis in Alzheimer's Disease: The Toxicity of Amyloid Beta (A beta ), Mechanisms of Its Accumulation and Implications of Medicinal Plants for Therapy. Evid Based Complement Alternat Med, 2013. 2013: p. 413808 .

[33] Manczak, M. and P.H. Reddy, Abnormal Interaction of Oligomeric Amyloid-beta with Phosphorylated Tau: Implications to Synaptic Dysfunction and Neuronal Damage. J Alzheimers Dis, 2013. 36(2): p. 285-95.

[34] Reddy, P.H., Amyloid beta-induced glycogen synthase kinase 3beta phosphorylated VDAC1 in Alzheimer's disease: Implications for synaptic dysfunction and neuronal damage. Biochim Biophys Acta, 2013.

[35] Magdesian, M.H., et al., Amyloid-beta binds to the extracellular cysteine-rich domain of Frizzled and inhibits Wnt/beta-catenin signaling. J Biol Chem, 2008. 283(14): p. 9359-68.

[36] Supnet, C. and I. Bezprozvanny, The dysregulation of intracellular calcium in Alzheimer disease. Cell Calcium, 2010. 47(2): p. 183-9.

[37] Supnet, C. and I. Bezprozvanny, Neuronal calcium signaling, mitochondrial dysfunction, and Alzheimer's disease. J Alzheimers Dis, 2010. 20 Suppl 2: p. S487-98. 
[38] Hynd, M.R., H.L. Scott, and P.R. Dodd, Glutamate-mediated excitotoxicity and neurodegeneration in Alzheimer's disease. Neurochem Int, 2004. 45(5): p. 583-95.

[39] Crimins, J.L., et al., The intersection of amyloid beta and tau in glutamatergic synaptic dysfunction and collapse in Alzheimer's disease. Ageing Res Rev, 2013.

[40] Boehm, J., A 'danse macabre': tau and Fyn in STEP with amyloid beta to facilitate induction of synaptic depression and excitotoxicity. Eur J Neurosci, 2013. 37(12): p. 1925-30.

[41] Robakis, N.K., et al., Chromosome 21q21 sublocalisation of gene encoding beta-amyloid peptide in cerebral vessels and neuritic (senile) plaques of people with Alzheimer disease and Down syndrome. Lancet, 1987. 1(8529): p. 384-5.

[42] Yoshikai, S., et al., Genomic organization of the human-amyloid beta-protein precursor gene. Gene, 1991. 102(2): p. 291-2.

[43] Jarrett, J.T., E.P. Berger, and P.T. Lansbury, Jr., The carboxy terminus of the beta amyloid protein is critical for the seeding of amyloid formation: implications for the pathogenesis of Alzheimer's disease. Biochemistry, 1993. 32(18): p. 4693-7.

[44] Puzzo, D., et al., Picomolar amyloid-beta positively modulates synaptic plasticity and memory in hippocampus. J Neurosci, 2008. 28(53): p. 14537-45.

[45] Lambert, M.P., et al., Diffusible, nonfibrillar ligands derived from Abeta1-42 are potent central nervous system neurotoxins. Proc Natl Acad Sci U S A, 1998. 95(11): p. 6448-53.

[46] Walsh, D.M. and D.J. Selkoe, Oligomers on the brain: the emerging role of soluble protein aggregates in neurodegeneration. Protein Pept Lett, 2004. 11(3): p. 213-28.

[47] Lacor, P.N., et al., Abeta oligomer-induced aberrations in synapse composition, shape, and density provide a molecular basis for loss of connectivity in Alzheimer's disease. J Neurosci, 2007. 27(4): p. 796-807.

[48] Cuello, A.C., Intracellular and extracellular Abeta, a tale of two neuropathologies. Brain Pathol, 2005. 15(1): p. 66-71.

[49] Selkoe, D.J., et al., The role of APP processing and trafficking pathways in the formation of amyloid beta-protein. Ann N Y Acad Sci, 1996. 777: p. 57-64.

[50] Walsh, D.M., et al., The oligomerization of amyloid beta-protein begins intracellularly in cells derived from human brain. Biochemistry, 2000. 39(35): p. 10831-9.

[51] Lesne, S.E., et al., Brain amyloid-beta oligomers in ageing and Alzheimer's disease. Brain, 2013. 136(Pt 5): p. 1383-98.

[52] Tomiyama, T., et al., A mouse model of amyloid beta oligomers: their contribution to synaptic alteration, abnormal tau phosphorylation, glial activation, and neuronal loss in vivo. J Neurosci, 2010. 30(14): p. 4845-56. 
[53] Yamamoto, N., et al., GM1-ganglioside-induced Abeta assembly on synaptic membranes of cultured neurons. Biochim Biophys Acta, 2007. 1768(5): p. 1128-37.

[54] McLaurin, J., et al., Structural transitions associated with the interaction of Alzheimer beta-amyloid peptides with gangliosides. J Biol Chem, 1998. 273(8): p. 4506-15.

[55] Oda, T., et al., Clusterin (apoJ) alters the aggregation of amyloid beta-peptide (A beta 1-42) and forms slowly sedimenting A beta complexes that cause oxidative stress. Exp Neurol, 1995. 136(1): p. 22-31.

[56] Stege, G.J., et al., The molecular chaperone alphaB-crystallin enhances amyloid beta neurotoxicity. Biochem Biophys Res Commun, 1999. 262(1): p. 152-6.

[57] Sakono, M. and T. Zako, Amyloid oligomers: formation and toxicity of Abeta oligomers. FEBS J, 2010. 277(6): p. 1348-58.

[58] Butterfield, S.M. and H.A. Lashuel, Amyloidogenic protein-membrane interactions: mechanistic insight from model systems. Angew Chem Int Ed Engl, 2010. 49(33): p. 5628-54.

[59] Kawahara, M., Neurotoxicity of beta-amyloid protein: oligomerization, channel formation, and calcium dyshomeostasis. Curr Pharm Des, 2010. 16(25): p. 2779-89.

[60] Valincius, G., et al., Soluble amyloid beta-oligomers affect dielectric membrane properties by bilayer insertion and domain formation: implications for cell toxicity. Biophys J, 2008. 95(10): p. 4845-61.

[61] De Felice, F.G., et al., Abeta oligomers induce neuronal oxidative stress through an $\mathrm{N}$-methyl-D-aspartate receptor-dependent mechanism that is blocked by the Alzheimer drug memantine. J Biol Chem, 2007. 282(15): p. 11590-601.

[62] Reddy, P.H. and M.F. Beal, Amyloid beta, mitochondrial dysfunction and synaptic damage: implications for cognitive decline in aging and Alzheimer's disease. Trends Mol Med, 2008. 14(2): p. 45-53.

[63] Shankar, G.M., et al., Natural oligomers of the Alzheimer amyloid-beta protein induce reversible synapse loss by modulating an NMDA-type glutamate receptor-dependent signaling pathway. J Neurosci, 2007. 27(11): p. 2866-75.

[64] Grundke-Iqbal, I., et al., Amyloid protein and neurofibrillary tangles coexist in the same neuron in Alzheimer disease. Proc Natl Acad Sci U S A, 1989. 86(8): p. 2853-7.

[65] Blurton-Jones, M. and F.M. Laferla, Pathways by which Abeta facilitates tau pathology. Curr Alzheimer Res, 2006. 3(5): p. 437-48.

[66] Wertkin, A.M., et al., Human neurons derived from a teratocarcinoma cell line express solely the 695-amino acid amyloid precursor protein and produce intracellular beta-amyloid or A4 peptides. Proc Natl Acad Sci U S A, 1993. 90(20): p. 9513-7. 
[67] Gouras, G.K., et al., Intraneuronal beta-amyloid accumulation and synapse pathology in Alzheimer's disease. Acta Neuropathol, 2010. 119(5): p. 523-41.

[68] Gouras, G.K., et al., Intraneuronal Abeta42 accumulation in human brain. Am J Pathol, 2000. 156(1): p. 15-20.

[69] LaFerla, F.M., K.N. Green, and S. Oddo, Intracellular amyloid-beta in Alzheimer's disease. Nat Rev Neurosci, 2007. 8(7): p. 499-509.

[70] Takahashi, R.H., et al., Co-occurrence of Alzheimer's disease ss-amyloid and tau pathologies at synapses. Neurobiol Aging, 2010. 31(7): p. 1145-52.

[71] Takahashi, R.H., et al., Accumulation of intraneuronal beta-amyloid 42 peptides is associated with early changes in microtubule-associated protein 2 in neurites and synapses. PLoS One, 2013. 8(1): p. e51965.

[72] Kokubo, H., et al., Soluble Abeta oligomers ultrastructurally localize to cell processes and might be related to synaptic dysfunction in Alzheimer's disease brain. Brain Res, 2005. 1031(2): p. 222-8.

[73] Hartmann, T., et al., Distinct sites of intracellular production for Alzheimer's disease A beta40/42 amyloid peptides. Nat Med, 1997. 3(9): p. 1016-20.

[74] Skovronsky, D.M., R.W. Doms, and V.M. Lee, Detection of a novel intraneuronal pool of insoluble amyloid beta protein that accumulates with time in culture. J Cell Biol, 1998. 141(4): p. 1031-9.

[75] Wild-Bode, C., et al., Intracellular generation and accumulation of amyloid beta-peptide terminating at amino acid 42. J Biol Chem, 1997. 272(26): p. 16085-8.

[76] Forloni, G., beta-Amyloid neurotoxicity. Funct Neurol, 1993. 8(3): p. 211-25.

[77] Forloni, G., et al., Apoptosis mediated neurotoxicity induced by chronic application of beta amyloid fragment 25-35. Neuroreport, 1993. 4(5): p. 523-6.

[78] Loo, D.T., et al., Apoptosis is induced by beta-amyloid in cultured central nervous system neurons. Proc Natl Acad Sci U S A, 1993. 90(17): p. 7951-5.

[79] Almeida, C.G., R.H. Takahashi, and G.K. Gouras, Beta-amyloid accumulation impairs multivesicular body sorting by inhibiting the ubiquitin-proteasome system. J Neurosci, 2006. 26(16): p. 4277-88.

[80] Oh, S., et al., Amyloid peptide attenuates the proteasome activity in neuronal cells. Mech Ageing Dev, 2005. 126(12): p. 1292-9.

[81] Tseng, B.P., et al., Abeta inhibits the proteasome and enhances amyloid and tau accumulation. Neurobiol Aging, 2008. 29(11): p. 1607-18.

[82] Butterfield, D.A. and R. Sultana, Methionine-35 of abeta(1-42): importance for oxidative stress in Alzheimer disease. J Amino Acids, 2011. 2011: p. 198430. 
[83] Christen, Y., Oxidative stress and Alzheimer disease. Am J Clin Nutr, 2000. 71(2): p. 621S-629S.

[84] Ramassamy, C., et al., Oxidative insults are associated with apolipoprotein E genotype in Alzheimer's disease brain. Neurobiol Dis, 2000. 7(1): p. 23-37.

[85] Sultana, R., et al., Increased protein and lipid oxidative damage in mitochondria isolated from lymphocytes from patients with Alzheimer's disease: insights into the role of oxidative stress in Alzheimer's disease and initial investigations into a potential biomarker for this dementing disorder. J Alzheimers Dis, 2011. 24(1): p. 77-84.

[86] Mattson, M.P., et al., beta-Amyloid peptides destabilize calcium homeostasis and render human cortical neurons vulnerable to excitotoxicity. J Neurosci, 1992. 12(2): p. 376-89.

[87] Hardy, J., et al., Region-specific loss of glutamate innervation in Alzheimer's disease. Neurosci Lett, 1987. 73(1): p. 77-80.

[88] Maragos, W.F., et al., Loss of hippocampal [3H]TCP binding in Alzheimer's disease. Neurosci Lett, 1987. 74(3): p. 371-6.

[89] Deshpande, A., et al., A role for synaptic zinc in activity-dependent Abeta oligomer formation and accumulation at excitatory synapses. J Neurosci, 2009. 29(13): p. 4004-15.

[90] Snyder, E.M., et al., Regulation of NMDA receptor trafficking by amyloid-beta. Nat Neurosci, 2005. 8(8): p. 1051-8.

[91] Roselli, F., et al., Soluble beta-amyloid1-40 induces NMDA-dependent degradation of postsynaptic density-95 at glutamatergic synapses. J Neurosci, 2005. 25(48): p. 11061-70.

[92] Frisardi, V., F. Panza, and A.A. Farooqui, Late-life depression and Alzheimer's disease: the glutamatergic system inside of this mirror relationship. Brain Res Rev, 2011. 67(1-2): p. 344-55.

[93] Walton, H.S. and P.R. Dodd, Glutamate-glutamine cycling in Alzheimer's disease. Neurochem Int, 2007. 50(7-8): p. 1052-66.

[94] Danbolt, N.C., Glutamate uptake. Prog Neurobiol, 2001. 65(1): p. 1-105.

[95] Hazell, A.S., et al., Selective down-regulation of the astrocyte glutamate transporters GLT-1 and GLAST within the medial thalamus in experimental Wernicke's encephalopathy. J Neurochem, 2001. 78(3): p. 560-8.

[96] Moriyama, Y. and H. Omote, Vesicular glutamate transporter acts as a metabolic regulator. Biol Pharm Bull, 2008. 31(10): p. 1844-6. 
[97] Danysz, W. and C.G. Parsons, Alzheimer's disease, beta-amyloid, glutamate, NMDA receptors and memantine--searching for the connections. Br J Pharmacol, 2012. 167(2): p. 324-52.

[98] Gao, S.F. and A.M. Bao, Corticotropin-releasing hormone, glutamate, and gammaaminobutyric acid in depression. Neuroscientist, 2011. 17(1): p. 124-44.

[99] Revett, T.J., et al., Glutamate system, amyloid ss peptides and tau protein: functional interrelationships and relevance to Alzheimer disease pathology. J Psychiatry Neurosci, 2013. 38(1): p. 6-23.

[100] Collingridge, G.L. and R.A. Lester, Excitatory amino acid receptors in the vertebrate central nervous system. Pharmacol Rev, 1989. 41(2): p. 143-210.

[101] Komuro, H. and P. Rakic, Modulation of neuronal migration by NMDA receptors. Science, 1993. 260(5104): p. 95-7.

[102] Rossi, D.J. and N.T. Slater, The developmental onset of NMDA receptor-channel activity during neuronal migration. Neuropharmacology, 1993. 32(11): p. 1239-48.

[103] Ottersen, O.P., et al., Ischemic disruption of glutamate homeostasis in brain: quantitative immunocytochemical analyses. J Chem Neuroanat, 1996. 12(1): p. 1-14.

[104] Ottersen, O.P., et al., Molecular organization of a type of peripheral glutamate synapse: the afferent synapses of hair cells in the inner ear. Prog Neurobiol, 1998. 54(2): p. 127-48.

[105] Gasparini, C.F. and L.R. Griffiths, The biology of the glutamatergic system and potential role in migraine. Int J Biomed Sci, 2013. 9(1): p. 1-8.

[106] Wenk, G.L., Neuropathologic changes in Alzheimer's disease: potential targets for treatment. J Clin Psychiatry, 2006. 67 Suppl 3: p. 3-7; quiz 23.

[107] Wenk, G.L., C.G. Parsons, and W. Danysz, Potential role of N-methyl-D-aspartate receptors as executors of neurodegeneration resulting from diverse insults: focus on memantine. Behav Pharmacol, 2006. 17(5-6): p. 411-24.

[108] Bell, K.F., D.A. Bennett, and A.C. Cuello, Paradoxical upregulation of glutamatergic presynaptic boutons during mild cognitive impairment. J Neurosci, 2007. 27(40): p. 10810-7.

[109] Fujikawa, D.G., Prolonged seizures and cellular injury: understanding the connection. Epilepsy Behav, 2005. 7 Suppl 3: p. S3-11.

[110] Won, S.J., D.Y. Kim, and B.J. Gwag, Cellular and molecular pathways of ischemic neuronal death. J Biochem Mol Biol, 2002. 35(1): p. 67-86.

[111] Yi, J.H. and A.S. Hazell, Excitotoxic mechanisms and the role of astrocytic glutamate transporters in traumatic brain injury. Neurochem Int, 2006. 48(5): p. 394-403. 
[112] Chen, K.H., et al., Disturbed neurotransmitter transporter expression in Alzheimer's disease brain. J Alzheimers Dis, 2011. 26(4): p. 755-66.

[113] Shigeri, Y., R.P. Seal, and K. Shimamoto, Molecular pharmacology of glutamate transporters, EAATs and VGLUTs. Brain Res Brain Res Rev, 2004. 45(3): p. 250-65.

[114] Kalariti, N., N. Pissimissis, and M. Koutsilieris, The glutamatergic system outside the CNS and in cancer biology. Expert Opin Investig Drugs, 2005. 14(12): p. 1487-96.

[115] Omote, H., et al., Vesicular neurotransmitter transporter: bioenergetics and regulation of glutamate transport. Biochemistry, 2011. 50(25): p. 5558-65.

[116] Kalandadze, A., Y. Wu, and M.B. Robinson, Protein kinase C activation decreases cell surface expression of the GLT-1 subtype of glutamate transporter. Requirement of a carboxyl-terminal domain and partial dependence on serine 486. J Biol Chem, 2002. 277(48): p. 45741-50.

[117] Robinson, M.B., Regulated trafficking of neurotransmitter transporters: common notes but different melodies. J Neurochem, 2002. 80(1): p. 1-11.

[118] Schoepfer, R., et al., Molecular biology of glutamate receptors. Prog Neurobiol, 1994. 42(2): p. 353-7.

[119] Mitchell, N.D. and G.B. Baker, An update on the role of glutamate in the pathophysiology of depression. Acta Psychiatr Scand, 2010. 122(3): p. 192-210.

[120] Kew, J.N. and J.A. Kemp, Ionotropic and metabotropic glutamate receptor structure and pharmacology. Psychopharmacology (Berl), 2005. 179(1): p. 4-29.

[121] Lau, C.G. and R.S. Zukin, NMDA receptor trafficking in synaptic plasticity and neuropsychiatric disorders. Nat Rev Neurosci, 2007. 8(6): p. 413-26.

[122] Mellone, M. and F. Gardoni, Modulation of NMDA receptor at the synapse: Promising therapeutic interventions in disorders of the nervous system. Eur J Pharmacol, 2013.

[123] Sanz-Clemente, A., R.A. Nicoll, and K.W. Roche, Diversity in NMDA receptor composition: many regulators, many consequences. Neuroscientist, 2013. 19(1): p. 62-75.

[124] Traynelis, S.F., et al., Glutamate receptor ion channels: structure, regulation, and function. Pharmacol Rev, 2010. 62(3): p. 405-96.

[125] Horak, M. and R.J. Wenthold, Different roles of C-terminal cassettes in the trafficking of full-length NR1 subunits to the cell surface. J Biol Chem, 2009. 284(15): p. 9683-91.

[126] Luscher, C., et al., Synaptic plasticity and dynamic modulation of the postsynaptic membrane. Nat Neurosci, 2000. 3(6): p. 545-50.

[127] Lozano, V.C., C. Armengaud, and M. Gauthier, Memory impairment induced by cholinergic antagonists injected into the mushroom bodies of the honeybee. J Comp Physiol A, 2001. 187(4): p. 249-54. 
[128] Maleszka, R., P. Helliwell, and R. Kucharski, Pharmacological interference with glutamate re-uptake impairs long-term memory in the honeybee, apis mellifera. Behav Brain Res, 2000. 115(1): p. 49-53.

[129] May-Simera, H. and E.D. Levin, NMDA systems in the amygdala and piriform cortex and nicotinic effects on memory function. Brain Res Cogn Brain Res, 2003. 17(2): p. 475-83.

[130] Si, A., P. Helliwell, and R. Maleszka, Effects of NMDA receptor antagonists on olfactory learning and memory in the honeybee (Apis mellifera). Pharmacol Biochem Behav, 2004. 77(2): p. 191-7.

[131] Wong, R.W., et al., Overexpression of motor protein KIF17 enhances spatial and working memory in transgenic mice. Proc Natl Acad Sci U S A, 2002. 99(22): p. 14500-5.

[132] Izquierdo, I. and J.H. Medina, Role of the amygdala, hippocampus and entorhinal cortex in memory consolidation and expression. Braz J Med Biol Res, 1993. 26(6): p. 573-89.

[133] Izquierdo, I., et al., Memory processing by the limbic system: role of specific neurotransmitter systems. Behav Brain Res, 1993. 58(1-2): p. 91-8.

[134] Rickard, N.S., K.T. Ng, and M.E. Gibbs, A nitric oxide agonist stimulates consolidation of long-term memory in the 1-day-old chick. Behav Neurosci, 1994. 108(3): p. 640-4.

[135] Rickard, N.S., et al., Both non-NMDA and NMDA glutamate receptors are necessary for memory consolidation in the day-old chick. Behav Neural Biol, 1994. 62(1): p. 33-40.

[136] Bezprozvanny, I. and P.R. Hiesinger, The synaptic maintenance problem: membrane recycling, Ca2+ homeostasis and late onset degeneration. Mol Neurodegener, 2013. 8: p. 23.

[137] Aksenov, M.Y., et al., Oxidative modification of glutamine synthetase by amyloid beta peptide. Free Radic Res, 1997. 27(3): p. 267-81.

[138] Blanchard, B.J., V.L. Thomas, and V.M. Ingram, Mechanism of membrane depolarization caused by the Alzheimer Abeta1-42 peptide. Biochem Biophys Res Commun, 2002. 293(4): p. 1197-203.

[139] Lue, L.F., et al., Soluble amyloid beta peptide concentration as a predictor of synaptic change in Alzheimer's disease. Am J Pathol, 1999. 155(3): p. 853-62.

[140] McLean, C.A., et al., Soluble pool of Abeta amyloid as a determinant of severity of neurodegeneration in Alzheimer's disease. Ann Neurol, 1999. 46(6): p. 860-6.

[141] Kayed, R., et al., Common structure of soluble amyloid oligomers implies common mechanism of pathogenesis. Science, 2003. 300(5618): p. 486-9. 
[142] Kakio, A., et al., Formation of a membrane-active form of amyloid beta-protein in raft-like model membranes. Biochem Biophys Res Commun, 2003. 303(2): p. 514-8.

[143] Lazarov, O., et al., Evidence that synaptically released beta-amyloid accumulates as extracellular deposits in the hippocampus of transgenic mice. J Neurosci, 2002. 22(22): p. 9785-93.

[144] Wang, D.S., et al., Oxidized neprilysin in aging and Alzheimer's disease brains. Biochem Biophys Res Commun, 2003. 310(1): p. 236-41.

[145] Yasojima, K., et al., Reduced neprilysin in high plaque areas of Alzheimer brain: a possible relationship to deficient degradation of beta-amyloid peptide. Neurosci Lett, 2001. 297(2): p. 97-100.

[146] Farris, W., et al., Loss of neprilysin function promotes amyloid plaque formation and causes cerebral amyloid angiopathy. Am J Pathol, 2007. 171(1): p. 241-51.

[147] Koffie, R.M., et al., Apolipoprotein E4 effects in Alzheimer's disease are mediated by synaptotoxic oligomeric amyloid-beta. Brain, 2012. 135(Pt 7): p. 2155-68.

[148] Albin, R.L. and J.T. Greenamyre, Alternative excitotoxic hypotheses. Neurology, 1992. 42(4): p. 733-8.

[149] Hu, N.W., T. Ondrejcak, and M.J. Rowan, Glutamate receptors in preclinical research on Alzheimer's disease: update on recent advances. Pharmacol Biochem Behav, 2012. 100(4): p. 855-62.

[150] Lacor, P.N., et al., Synaptic targeting by Alzheimer's-related amyloid beta oligomers. J Neurosci, 2004. 24(45): p. 10191-200.

[151] Palop, J.J. and L. Mucke, Amyloid-beta-induced neuronal dysfunction in Alzheimer's disease: from synapses toward neural networks. Nat Neurosci, 2010. 13(7): p. 812-8.

[152] Selkoe, D.J., Alzheimer's disease is a synaptic failure. Science, 2002. 298(5594): p. 789-91.

[153] Wogulis, M., et al., Nucleation-dependent polymerization is an essential component of amyloid-mediated neuronal cell death. J Neurosci, 2005. 25(5): p. 1071-80.

[154] Shankar, G.M., et al., Amyloid-beta protein dimers isolated directly from Alzheimer's brains impair synaptic plasticity and memory. Nat Med, 2008. 14(8): p. 837-42.

[155] Mucke, L. and D.J. Selkoe, Neurotoxicity of amyloid beta-protein: synaptic and network dysfunction. Cold Spring Harb Perspect Med, 2012. 2(7): p. a006338.

[156] Cullen, W.K., et al., Block of LTP in rat hippocampus in vivo by beta-amyloid precursor protein fragments. Neuroreport, 1997. 8(15): p. 3213-7.

[157] Oddo, S., et al., Triple-transgenic model of Alzheimer's disease with plaques and tangles: intracellular Abeta and synaptic dysfunction. Neuron, 2003. 39(3): p. 409-21. 
[158] Hsia, A.Y., et al., Plaque-independent disruption of neural circuits in Alzheimer's disease mouse models. Proc Natl Acad Sci U S A, 1999. 96(6): p. 3228-33.

[159] Tseng, B.P., M. Kitazawa, and F.M. LaFerla, Amyloid beta-peptide: the inside story. Curr Alzheimer Res, 2004. 1(4): p. 231-9.

[160] LaFerla, F.M. and S. Oddo, Alzheimer's disease: Abeta, tau and synaptic dysfunction. Trends Mol Med, 2005. 11(4): p. 170-6.

[161] Lauren, J., et al., Cellular prion protein mediates impairment of synaptic plasticity by amyloid-beta oligomers. Nature, 2009. 457(7233): p. 1128-32.

[162] Um, J.W., et al., Alzheimer amyloid-beta oligomer bound to postsynaptic prion protein activates Fyn to impair neurons. Nat Neurosci, 2012. 15(9): p. 1227-35.

[163] Mairet-Coello, G., et al., The CAMKK2-AMPK kinase pathway mediates the synaptotoxic effects of Abeta oligomers through Tau phosphorylation. Neuron, 2013. 78(1): p. 94-108.

[164] Cai, Z., et al., Roles of AMP-activated protein kinase in Alzheimer's disease. Neuromolecular Med, 2012. 14(1): p. 1-14.

[165] Scheff, S.W., et al., Synaptic alterations in CA1 in mild Alzheimer disease and mild cognitive impairment. Neurology, 2007. 68(18): p. 1501-8.

[166] Spires, T.L., et al., Dendritic spine abnormalities in amyloid precursor protein transgenic mice demonstrated by gene transfer and intravital multiphoton microscopy. J Neurosci, 2005. 25(31): p. 7278-87.

[167] Lacor, P.N., Advances on the understanding of the origins of synaptic pathology in AD. Curr Genomics, 2007. 8(8): p. 486-508.

[168] Bittner, T., et al., Amyloid plaque formation precedes dendritic spine loss. Acta Neuropathol, 2012. 124(6): p. 797-807.

[169] Selkoe, D.J., Soluble oligomers of the amyloid beta-protein impair synaptic plasticity and behavior. Behav Brain Res, 2008. 192(1): p. 106-13.

[170] Kirkwood, C.M., et al., Dendritic Spine Density, Morphology, and Fibrillar Actin Content Surrounding Amyloid-beta Plaques in a Mouse Model of Amyloid-beta Deposition. J Neuropathol Exp Neurol, 2013. 72(8): p. 791-800.

[171] Sivanesan, S., A. Tan, and J. Rajadas, Pathogenesis of Abeta oligomers in synaptic failure. Curr Alzheimer Res, 2013. 10(3): p. 316-23.

[172] Tyan, S.H., et al., Amyloid precursor protein (APP) regulates synaptic structure and function. Mol Cell Neurosci, 2012. 51(1-2): p. 43-52.

[173] Townsend, M., et al., Effects of secreted oligomers of amyloid beta-protein on hippocampal synaptic plasticity: a potent role for trimers. J Physiol, 2006. 572(Pt 2): p. 477-92. 
[174] Wu, H.Y., et al., Distinct dendritic spine and nuclear phases of calcineurin activation after exposure to amyloid-beta revealed by a novel fluorescence resonance energy transfer assay. J Neurosci, 2012. 32(15): p. 5298-309.

[175] Penzes, P., et al., Dendritic spine pathology in neuropsychiatric disorders. Nat Neurosci, 2011. 14(3): p. 285-93.

[176] Puzzo, D., L. Privitera, and A. Palmeri, Hormetic effect of amyloid-beta peptide in synaptic plasticity and memory. Neurobiol Aging, 2012. 33(7): p. 1484 e15-24.

[177] Seabrook, G.R., et al., Mechanisms contributing to the deficits in hippocampal synaptic plasticity in mice lacking amyloid precursor protein. Neuropharmacology, 1999. 38(3): p. 349-59.

[178] Rezvani, A.H., Involvement of the NMDA System in Learning and Memory. 2006.

[179] Saura, C.A., et al., Loss of presenilin function causes impairments of memory and synaptic plasticity followed by age-dependent neurodegeneration. Neuron, 2004. 42(1): p. 23-36.

[180] Ma, H., et al., Involvement of beta-site APP cleaving enzyme 1 (BACE1) in amyloid precursor protein-mediated enhancement of memory and activity-dependent synaptic plasticity. Proc Natl Acad Sci U S A, 2007. 104(19): p. 8167-72.

[181] Laird, F.M., et al., BACE1, a major determinant of selective vulnerability of the brain to amyloid-beta amyloidogenesis, is essential for cognitive, emotional, and synaptic functions. J Neurosci, 2005. 25(50): p. 11693-709.

[182] Texido, L., et al., Amyloid beta peptide oligomers directly activate NMDA receptors. Cell Calcium, 2011. 49(3): p. 184-90.

[183] MacDermott, A.B., et al., NMDA-receptor activation increases cytoplasmic calcium concentration in cultured spinal cord neurones. Nature, 1986. 321(6069): p. 519-22.

[184] Peng, T.I. and M.J. Jou, Oxidative stress caused by mitochondrial calcium overload. Ann N Y Acad Sci, 2010. 1201: p. 183-8.

[185] Gerzon, K., et al., The Adamantyl Group in Medicinal Agents. I. Hypoglycemic NArylsulfonyl-N' -Adamantylureas. J Med Chem, 1963. 6: p. 760-3.

[186] Chen, H.S. and S.A. Lipton, Mechanism of memantine block of NMDA-activated channels in rat retinal ganglion cells: uncompetitive antagonism. J Physiol, 1997. 499 (Pt 1): p. 27-46.

[187] Kornhuber, J., et al., Memantine displaces [3H]MK-801 at therapeutic concentrations in postmortem human frontal cortex. Eur J Pharmacol, 1989. 166(3): p. 589-90.

[188] Rogawski, M.A. and G.L. Wenk, The neuropharmacological basis for the use of memantine in the treatment of Alzheimer's disease. CNS Drug Rev, 2003. 9(3): p. 275-308. 
[189] Minkeviciene, R., P. Banerjee, and H. Tanila, Memantine improves spatial learning in a transgenic mouse model of Alzheimer's disease. J Pharmacol Exp Ther, 2004. 311(2): p. $677-82$.

[190] Filali, M., R. Lalonde, and S. Rivest, Subchronic memantine administration on spatial learning, exploratory activity, and nest-building in an APP/PS1 mouse model of Alzheimer's disease. Neuropharmacology, 2011. 60(6): p. 930-6.

[191] Van Dam, D. and P.P. De Deyn, Cognitive evaluation of disease-modifying efficacy of galantamine and memantine in the APP23 model. Eur Neuropsychopharmacol, 2006. 16(1): p. 59-69.

[192] Martinez-Coria, H., et al., Memantine improves cognition and reduces Alzheimer'slike neuropathology in transgenic mice. Am J Pathol, 2010. 176(2): p. 870-80.

[193] Dong, H., et al., Effects of memantine on neuronal structure and conditioned fear in the Tg2576 mouse model of Alzheimer's disease. Neuropsychopharmacology, 2008. 33(13): p. 3226-36.

[194] Rive, B., et al., Memantine enhances autonomy in moderate to severe Alzheimer's disease. Int J Geriatr Psychiatry, 2004. 19(5): p. 458-64.

[195] Peskind, E.R., et al., Memantine treatment in mild to moderate Alzheimer disease: a 24-week randomized, controlled trial. Am J Geriatr Psychiatry, 2006. 14(8): p. 704-15.

[196] Reisberg, B., et al., A 24-week open-label extension study of memantine in moderate to severe Alzheimer disease. Arch Neurol, 2006. 63(1): p. 49-54.

[197] Ferris, S., et al., Treatment effects of Memantine on language in moderate to severe Alzheimer's disease patients. Alzheimers Dement, 2009. 5(5): p. 369-74. 
